\begin{tabular}{|c|c|c|}
\hline $\begin{array}{l}\text { PKS } \\
\text { PUBLIC } \\
\text { KNDOLEDGE } \\
\text { PROJECT }\end{array}$ & $\begin{array}{c}\text { REVISTA DE GEOGRAFIA } \\
\text { (RECIFE) } \\
\text { nttp://www.revista.ufpe.br/revistageografia }\end{array}$ & $\begin{array}{l}\text { OJS } \\
\text { OPEN } \\
\text { JOUNAL } \\
\text { SYSTEMS }\end{array}$ \\
\hline
\end{tabular}

\title{
DINÂMICA TERRITORIAL DO LITORAL MERIDIONAL DO ESTADO DE ALAGOAS - BRASIL
}

\author{
Silvana Quintella Cavalcanti Calheiros ${ }^{2}$, Paulo Rogério de Freitas Silva ${ }^{2}$
}

\author{
${ }^{1}$ Instituto de Geografia, Desenvolvimento e Meio Ambiente da Universidade Federal de Alagoas. Email: \\ qsilvana@uol.com.br \\ ${ }^{2}$ Instituto de Geografia, Desenvolvimento e Meio Ambiente da Universidade Federal de Alagoas. Email: \\ paulgeografia@gmail.com
}

Artigo recebido em 08/05/2017 e aceito em 09/06/2017

\begin{abstract}
RESUMO
Buscamos investigar a influência do turismo na organização territorial do litoral meridional do estado de Alagoas, considerando as alterações e relações espaciais produzidas sobre uma estrutura ambiental e socioeconômica, dominada tradicionalmente pela agricultura da cana-de-açúcar e do coco. A abordagem teórica/conceitual circunscrita a esta investigação está estruturada no tripé Geografia, Análise Ambiental e Geoprocessamento, pela vinculação existente entre a pesquisa ambiental, os Sistemas Geográficos de Informação (SGI) e os princípios científicos que norteiam a ciência geográfica. A ênfase da investigação recai sobre a realização de análises de situações ambientais relevantes identificadas, geograficamente discerníveis sobre o território. Para realização desta pesquisa utilizou-se metodologia de Análise Ambiental desenvolvida pelo Laboratório de Geoprocessamento do Departamento de Geografia da Universidade Federal do Rio de Janeiro, que criou o SAGA - Sistema de Análise Geo-Ambiental. Este SGI permite realizar as análises (diagnósticos e prognósticos) sobre uma base de dados georreferenciada, previamente inventariada e armazenada em meio digital. A base de dados constitui-se de diversos mapas temáticos e sobre esta base foram realizadas planimetrias, análises prospectivas (assinaturas ambientais) e evolutivas (monitoramento) e avaliações ambientais das situações ambientais identificadas. Estas avaliações conduziram à delimitação de áreas potenciais conflitantes, entre turismo e a agricultura dominante, demonstrando a ocorrência de situações de disputa territorial por recursos geoambientais, traduzindo-se em novas relações territoriais.
\end{abstract}

Palavras-chave: Alagoas; conflitos; geoprocessamento; ocupação; turismo.

\section{TERRITORIAL DYNAMICS OF THE SOUTHERN COAST OF THE STATE OF ALAGOAS - BRAZIL}

\begin{abstract}
The research aims to investigate the influence of tourism on the territorial organization of the southern coast of the state of Alagoas, taking into consideration the changes and spatial relationships create on an environmental and socioeconomic structure traditionally dominated by sugar cane and coconut agriculture. The theoretical and conceptual approach circumscribed to this research is structurally based on the Geography, Environmental Analysis and Geoprocessing tripod by the existent link between environmental research, Geographic Information Systems (SGI) and the scientific principles that guide geographic science. The emphasis of the research act on the execution of identified relevant environmental situations geographically discernible to the territory. To perform this research an Environmental Analysis methodology developed by the Geoprocessing Laboratory of the Department of Geography of the Federal University of Rio de Janeiro was used, which created the SAGA Geo-Environmental Analysis System. The Geographic Information Systems (SGI) allows performing the analyzes - diagnostics and prognostics on a georeferenced database previously inventoried and stored in a digital medium. The database is made up of several thematic maps upon of which were performed planimetry, prospective analysis (environmental signatures) and evolutionary (monitoring) and, environmental assessments of the identified environmental situations were carried out. These assessments led to the delineation of
\end{abstract}


conflicting potential areas between tourism and the dominant agriculture demonstrating the incidence of territorial dispute situations by geoenvironmental resources, translating into new territorial relations.

Key-words: Alagoas; conflicts; geoprocessamento; occupation; tourism

\section{INTRODUÇÃO}

A atividade turística movimenta em nível mundial segundo Rodrigues (1996, p.32), um grande volume de pessoas e de capital, inscrevendo-se materialmente de forma cada vez mais significativa ao criar e recriar espaços diversificados. Suas distintas expressões espaciais ocorrem em vários níveis, desde escalas regionais ou locais dentro de um mesmo país, até planetária, não poupando nenhum território: zonas glaciais, cadeias terciárias, na cidade, no campo, nas florestas, desertos, oceanos, mares, lagos, rios, regiões submarinas e regiões litorâneas.

Rodrigues (1977, p.15) afirma que no período atual são os grandes geossistemas do mundo tropical, até então preservados, em particular dos continentes africanos e latinoamericanos, que se tornam alvo da expansão turística. No Brasil o turismo vem ocorrendo em escala crescente; exemplos são conhecidos desde a Amazônia até o litoral brasileiro, sendo no segundo de forma mais intensa.

No litoral brasileiro a recente importância da atividade turística encontra-se principalmente na costa nordestina. Segundo Becker (1996, p.20) duas situações são de grande importância para a expansão do turismo, o primeiro diz respeito à grande atratividade turística deste litoral devido, as condições climáticas favoráveis (quente durante todo o ano e com altos índices de insolação) permitem seu aproveitamento para lazer e recreação durante todo o ano, constituindo-se em uma das molas propulsoras desta atividade econômica; a presença de formações litorâneas típicas de litorais tropicais (dunas, recifes, lagunas, restingas entre outras); a composição paisagística dos ambientes litorâneos (restinga-mar-coqueiro, dunas-mar-rio-vegetação, entre outras). O segundo está relacionado à extensão do litoral que apresenta as características acima citadas. Verifica-se que os estados que compõem a região são todos litorâneos e somados resultam em aproximadamente $3.300 \mathrm{~km}$ de litoral, o que representa quase $50 \%$ dos cerca de 7.000 quilômetros do litoral brasileiro.

No caso do estado de Alagoas, com 270 quilômetros de orla, o turismo estruturado como atividade econômica produtiva teve início em 1986 com a criação da EMATUR Empresa Alagoana de Turismo e a partir da iniciativa privada, com a implantação do Hotel Jatiúca, consolidou o estado como um dos principais polos de turismo do Nordeste. 
Atualmente, além da presença do turismo na porção central do litoral alagoano, mais precisamente Maceió e sua região metropolitana, o mesmo apresenta ocorrência no Norte com o Projeto Costa Dourada e no litoral Sul onde se constata a implantação de rede hoteleira e a construção de condôminos de "veraneio", conforme aponta Calheiros (1990, p.6 e 1994, p.10) quando se refere as transformações e impactos diferenciados ocorridos ao longo do litoral alagoano.

O litoral central é a área em que maiores alterações são causadas pela atuação antrópica, pois apresenta maior concentração populacional, expansão urbana desordenada e, um polo turístico e industrial. No litoral norte a atuação antrópica deu-se pela agricultura baseada na indústria açucareira e, mais recentemente, pelo turismo associado à urbanização. Já o litoral sul que compreende os municípios de Piaçabuçú, Feliz Deserto, Coruripe, Jequiá da Praia e Roteiro, apresenta-se com menor intervenção antrópica, possuindo ainda ecossistemas com pouco ou nenhum grau de alteração, quando comparado aos demais segmentos do litoral. Considerando a entrada do turismo nesse litoral sul do estado de Alagoas, se constata situações de intervenções antrópicas inicias que comprometem o meio ambiente mediante as diferentes formas de atuação, causando alterações e impactos.

Os impactos ambientais nesse litoral sul, resultantes da atividade turística identificados, mediante as relações espaciais estabelecidas pela penetração do turismo numa área tradicionalmente agrícola, está provocando disputas dos seus recursos naturais, humanos e de infraestrutura, gerando relações de conflito e, consequentemente, originando nova organização territorial. Nessa perspectiva, buscamos analisar esse processo nos municípios de Coruripe, Feliz Deserto e Piaçabuçú, (Figura 01), que se estendem entre as coordenadas geográficas $36^{\circ} 10^{\prime} 32^{\prime \prime} \mathrm{W}, 10^{\circ} 07^{\prime} 32^{\prime \prime S}$ e $36^{\circ} 26^{\prime} 04^{\prime \prime} \mathrm{W}, 10^{\circ} 24^{\prime} 20^{\prime \prime} \mathrm{S}$, correspondendo a uma área aproximadamente de 1.306,5 quilômetros quadrados. 


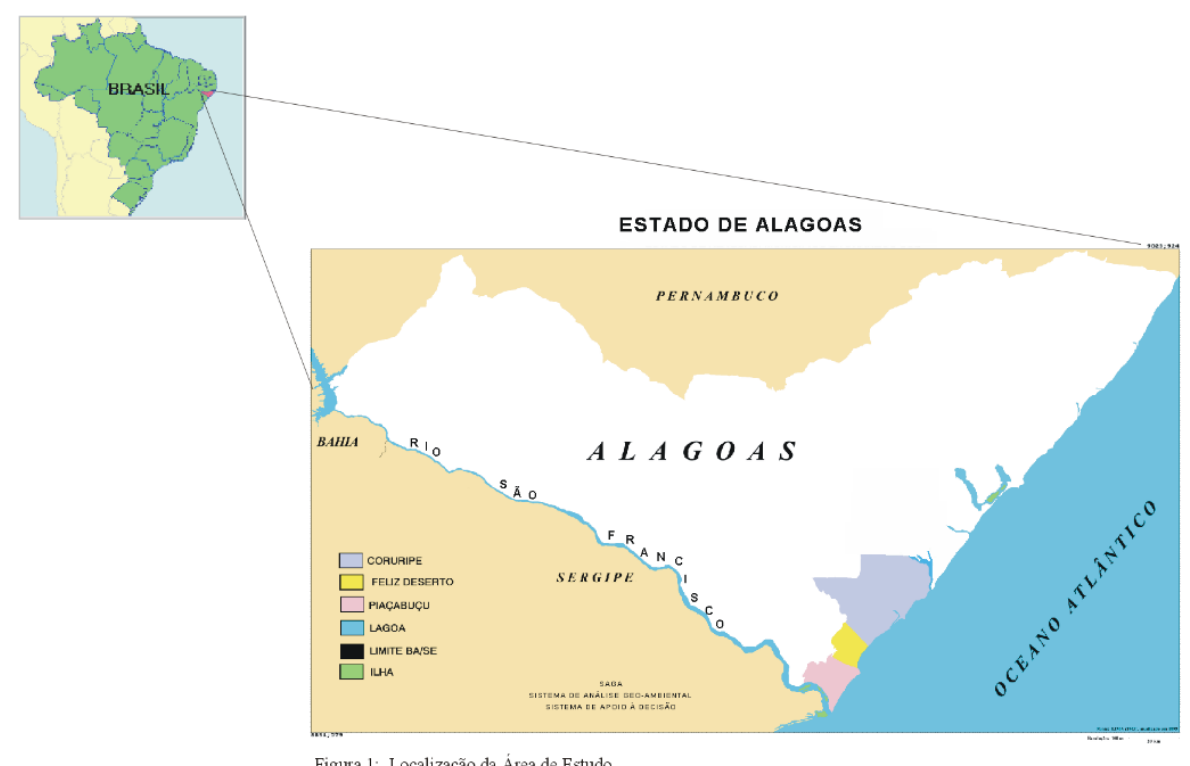

Figura1: Localização da área de estudo

O atual quadro geográfico desses municípios é dominado pela cultura da cana-deaçúcar (tabuleiros costeiros e várzeas), do coco (tabuleiros costeiros, cordões litorâneos e paleofeixes de dunas deltaicas), pela pesca (no litoral e baixo curso do São Francisco) e também pelo cultivo do arroz (baixo curso do São Francisco).

Sendo assim, sendo o turismo um fenômeno social de grande expressividade conforme cita Padilha, (1990, p.10, representa uma atividade em expansão, não só do ponto de vista econômico, mas também, em termos territoriais, sendo um grande consumidor de espaços e, consequentemente, produtor e transformador destes como destaca Cara, (1997, p.8), buscamos analisar como está se processando esse fenômeno nessa área.

Considerado por alguns como uma indústria de viagens de prazer trata-se de algo mais complexo do que um simples negócio ou comércio. Para Burkart \& Medlink (1974) o turismo é um amálgama de fenômenos que surge por causa do movimento de pessoas e sua permanência em vários destinos. A definição mais detalhada está em De La Torre (1992, p.5) ao afirmar que:

(...) o turismo é um fenômeno social que consiste no deslocamento voluntário e temporário de indivíduos ou grupos de pessoas que, fundamentalmente por motivos de recreação, descanso, cultura ou saúde saem do seu lugar de residência habitual para outro, no qual não exercem nenhuma atividade lucrativa ou remunerada, gerando múltiplas interrelações de importância social, econômica e cultural.

Porém, além de ser um fenômeno social complexo este é diversificado, pois existem vários tipos de turismo que podem ser classificados por diferentes critérios. Os tipos de 
turismo encontrados na área de estudo, definida anteriormente como litoral sul de Alagoas, se inserem na classificação apresentada em Barreto (1995, p.10) levando em consideração três critérios:
A. De acordo com a duração: turismo de fim-de-semana e de férias;
B. Quanto ao tipo de alojamento: rede hoteleira e;
C. Quanto ao interesse: ecológico.

Assim tipos de turismo investigados no litoral sul alagoano permitem associá-los a uma estrutura geograficamente definível, Xavier-da-Silva, (1998, p.6), enquanto expressão territorial, detectável nas alterações físico-antrópicas em função de sua presença; sendo, portanto, analisáveis por geoprocessamento.

Neste sentido, os SGIs são sistemas destinados ao tratamento de dados referenciados espacialmente, que permitem recuperar, combinar e alterar informações, bem como efetuar os mais diversos tipos de análise sobre os dados (Alves, 1990, p.12). Enfim, com técnicas de geoprocessamento é possível investigar situações ambientais implicitamente contidas na massa de dados atualizáveis do SGI, segundo condições específicas a serem equacionadas e prognosticadas (Xavier-da-Silva, 1992, p. 5).

Correlacionando com os conceitos acima explanados sobre a execução da presente pesquisa pode-se afirmar que foram campeadas informações sobre o litoral sul alagoano, com base na criação de um modelo digital daquele ambiente geográfico, composto por planos de informação que foram analisados por geoprocessamento, visando à definição de condições de conflito territorial entre a expansão do turismo e a atividade agrícola da cana-de-açúcar.

A obtenção geral dos dados foi realizada a partir de trabalho de campo, análises estatísticas e interpretações de documentos cartográficos e de imagens de satélites e consultas a bancos de dados tendo, como produto final a identificação dos fenômenos e eventos.

No que se refere ao material utilizado, elencamos as bases cartográficas digitais, estruturadas em um Sistema Geográfico de Informação dos Municípios litorâneos meridionais Sul (Coruripe, Feliz Deserto e Piaçabuçú) do Laboratório de Geoprocessamento Aplicado (LGA) IGDEMA UFAL, resolução 25 metros de 2008. Entre os Softwares utilizados, destacamos o Vista S.A.G.A/UFRJ que é um sistema geográfico de informação (SGI), desenvolvido pelo Laboratório de Geoprocessamento-LAGEOP, visando aplicações ambientais. O módulo de análise ambiental visa satisfazer uma necessidade atual, principalmente daqueles que lidam rotineiramente com a área ambiental, qual seja: a 
possibilidade de analisar dados georreferenciados e convencionais, fornecendo como resultados mapas e relatórios que irão apoiar o processo de tomada de decisão.

Com relação ao trabalho de campo, as primeiras atividades foram de reconhecimentos da realidade ambiental realizadas com mapas, imagens e aerofotos, que orientaram as inspeções e amostragens feitas, sempre que possível utilizando uma visão diacrônica.

\section{ANÁLISE POR GEOPROCESSAMENTO}

Análise dos dados por geoprocessamento baseia-se na proposta metodológica apresentada por Xavier-da-Silva e Carvalho Filho (1993, p.18) e ampliada em Xavier-daSilva (1999, p.20), no que se refere o procedimento de avaliação esquematizada na Figura 2.

As avaliações constituem uma forma de prospecção ambiental, segundo a metodologia adotada por Xavier-da-Silva e Carvalho Filho, (1993, p.14) e possui a finalidade de delimitação de áreas específicas para uma determinada utilização (risco e potencial), baseando-se nas características ambientais contidas na base de dados georreferenciada. Alicerçada em condições ambientais previamente inventariadas e também em situações ambientais previamente identificadas, as avaliações contribuem para o conhecimento da estrutura comportamental do ambiente. As condições previamente inventariadas passam a ser à base de dados georreferenciadas dos Municípios litorâneos meridionais Sul (Coruripe, Feliz Deserto e Piaçabuçú). As avaliações resultam em classificações do espaço geográfico baseadas nos levantamentos de conjugações de características ambientais representadas na base de dados inventariada. Estas podem gerar mapeamentos de riscos e potenciais ambientais.

Para atender os objetivos diante da abordagem metodológica adotada, fez-se um tipo de avaliação complexa: potenciais conflitantes corresponde ao confronto de dois potenciais, resultando em prejuízos mútuos para os potenciais como também indicam o nível destes prejuízos, objetivando apontar para necessidades de conciliação dos potenciais.

A identificação de áreas potenciais conflitantes pelo uso mútuo dos recursos ambientais ao definir áreas de confronto entre potenciais ambientais permitirá tomada de decisão quanto às intervenções de manejo ambiental. 


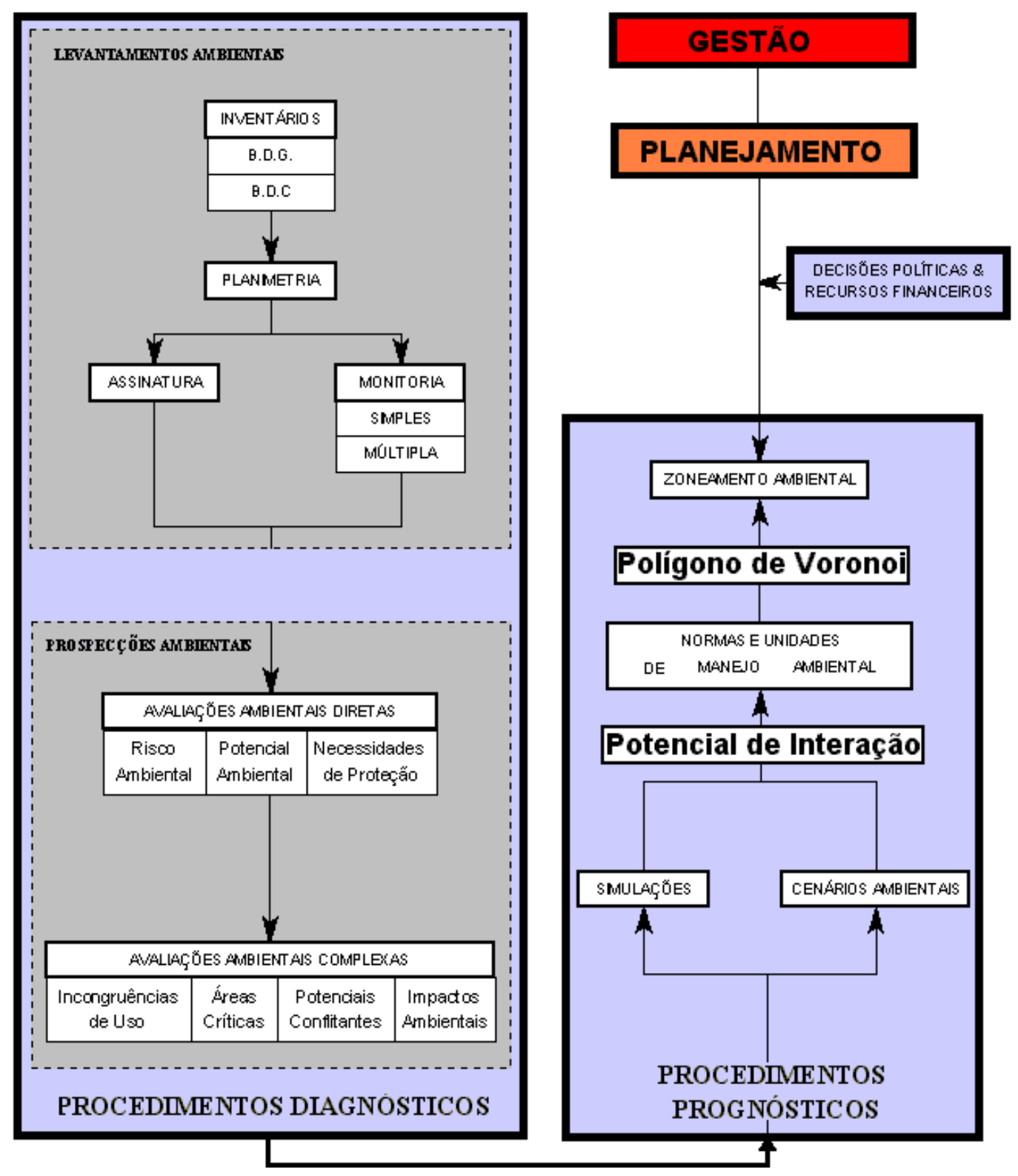

Figura 2. Proposta metodológica de Xavier-da-Silva e Carvalho Filho, (1993 e ampliada em Xavier-da-

Silva, (1999).

Esta análise respondeu pela identificação de áreas potenciais conflitantes pelo uso mútuo dos recursos ambientais das situações ambientais avaliadas, definindo áreas potenciais conflitantes corresponde ao confronto de dois potenciais, resultando em prejuízos mútuos para os potenciais como também indicam o nível destes prejuízos, objetivando apontar para necessidades de conciliação dos potenciais.

Neste estudo o uso dessa avaliação permitiu a identificação de áreas potenciais conflitantes pelo uso mútuo dos recursos ambientais das situações ambientais avaliadas, definindo áreas de disputa territorial verificada pelo confronto entre potenciais ambientais 
cujo conhecimento permitirá tomada de decisão quanto às intervenções de manejo ambiental. As avaliações foram expostas em cartogramas digitais e quadros-sínteses.

O SAGA/UFRJ, descrito anteriormente, apresenta um módulo próprio para realização das avaliações ambientais, pois consiste no entrecruzamento dos mapas utilizandose média aritmética ponderada. Cada mapa, ao fazer parte da avaliação, é ponderado pela utilização de pesos, segundo sua importância relativa. Postula-se que o conjunto de mapas compõe $100 \%$ da responsabilidade pela situação ambiental analisada. As classes recebem notas (0-10 ou 0-100), segundo a possibilidade de associação da classe com a ocorrência do fenômeno estudado. Resultam em um mapa final que expressa níveis semelhantes de risco ou de potencial para a ocorrência do fenômeno estudado. A avaliação para identificação de áreas de conflitantes, objeto desse trabalho se definiu pela participação de cada parâmetro correspondeu a 50, com respectivas notas de 0 a 10.

\section{RESULTADOS E DISCUSSÕES}

A natureza da territorialidade dos fenômenos analisados em suas potencialidades ambientais territoriais nos remete à análise definidora de áreas de ocorrência de situações potenciais conflitantes. Para o litoral sul alagoano, a avaliação de potenciais conflitantes foi composta em relação aos cultivos de cana-de-açúcar e coqueiro e ao turismo. Apesar de cada um desses potenciais apresentarem seus "ambientes" próprios (área de tabuleiros e baixada costeira), observam-se dois fatos importantes que induziram essa integração deliberada ou natural:

1. "penetração" do cultivo do coco, no "domínio" da cana, através de vales tabuliformes;

2. A integração "simbiótica" entre o potencial turístico e o domínio do coqueiro ao longo da baixada costeira. Daí a relação conflituosa desses potenciais.

Com apoio de monitorias, nas assinaturas ambientais e nas avaliações dos potenciais executados, áreas de potenciais conflitantes foram identificadas e analisadas. O procedimento analítico conduziu à identificação de áreas reveladoras desta relação conflituosa entre a agricultura da cana-de-açúcar com a atividade turística.

\section{SITUAÇÕES AMBIENTAIS CONFLITANTES ANALISADAS}

Consultas a estudos existentes, a análise dos resultados das monitorias e assinaturas 
realizadas, conduziram a análise de relações espaciais de conflito entre o cultivo da cana-deaçúcar e os diferentes tipos de turismo quanto a uso dos recursos ambientais. Foram analisadas três situações conflitantes.

1. Áreas Conflitantes entre Potencial para Cultivo de Cana X Potencial Turístico de Veraneio.

2. Áreas Conflitantes entre Potencial para Cultivo de Cana X Potencial Turístico de Fim de semana.

3. Áreas Conflitantes entre Potencial para Cultivo de Cana X Potencial Turístico de Empreendimentos.

Seleção dos parâmetros para análise de potenciais conflitantes para cana e turismo de veraneio, fim de semana e empreendimentos no litoral meridional alagoano.

Os parâmetros utilizados para esta análise corresponderam às Áreas Potenciais para Cultivo de Cana-de-açúcar e Áreas Potenciais para turismo de Veraneio, Fim de Semana e Empreendimento. Os parâmetros utilizados para esta análise corresponderam a: Áreas Potenciais para Movimentos de Massa, Áreas Potenciais para Enchentes e Mapa de População de Maceió-2010. Para efetivar as análises foram selecionados os parâmetros, expostos abaixo (Figuras 3, 4,5 e 6).

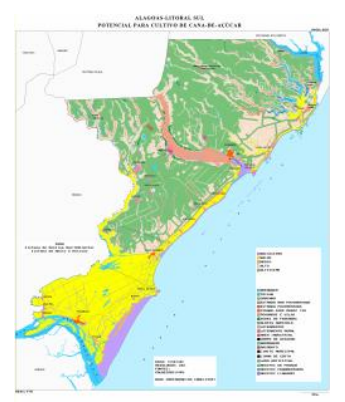

Figura 3: Potencial para Cana-de-açúcar

Calheiros (2000) 


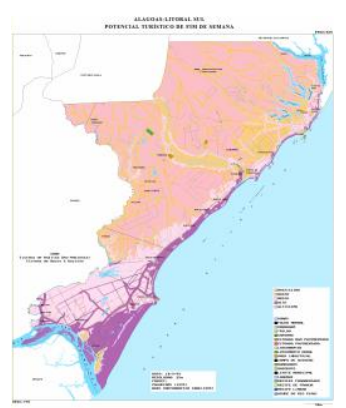

Figura

Veraneio

Calheiros (2000)

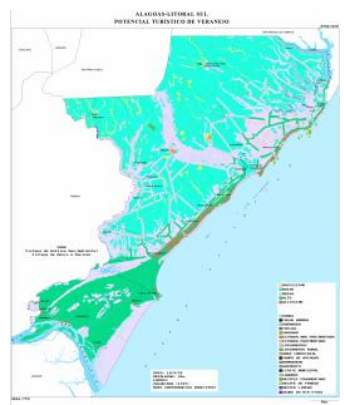

Figura5: Potencial Turismo

Fim de Semana

Calheiros (2000)

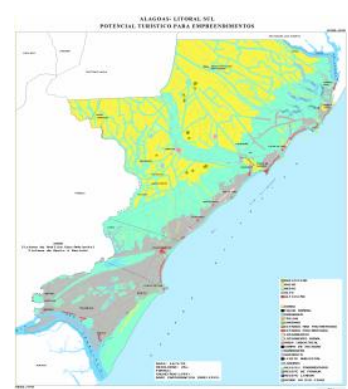

Figura 6: Potencial Turismo Empreendimento

Calheiros (2000)

Em seguida esses cartogramas foram atualizados em seus limites, devido parte da área ao norte ter sido desmembrada para compor a criação do município de Jequiá da Praia.

\section{ÁREAS DE CONFLITO ENTRE O POTENCIAL DE CANA-DE-AÇÚCAR E O POTENCIAL TURÍSTICO}

A análise tem sua importância por constatar a penetração da atividade turística, sobre a área de cana-de-açúcar, atividade agrícola tradicional de importante área plantada assistida por indústrias de açúcar e destilarias de álcool, caracterizando-se por uma competição territorial de atividade de expressão espacial diferenciada, agrícola versus urbana.

Conflito entre os potenciais de cana-de-açúcar e turístico de veraneio

Embora não apresente expressiva área territorial conflitante, segundo a tabela 1 às unidades delimitadas, conforme a figura 7, evidenciam a existência de confronto entre os potenciais, pela disputa de área pelo turismo de veraneio para uso e ocupação de uma área historicamente e naturalmente ocupada.

TABELA 1 - Resultado do Conflito dos Potenciais de Cana e Turismo de Veraneio

\begin{tabular}{l|r|r}
\hline \multicolumn{1}{c|}{ CLASSES } & \multicolumn{1}{c|}{ Há } & \multicolumn{1}{c}{ \% } \\
\hline SEM CONFLITO & 123741,0 & 98,0 \\
\hline ALTA CANA-DE-AÇÚCAR X ALTO TURISMO DE VERANEIO & 2743,0 & 2,0 \\
\hline
\end{tabular}

A distribuição espacial ocorreu em 2 áreas: 
Área 1 - Unidades territoriais contínuas distribuídas sobre a rede viária, entre os povoados de Poxim e Pontal de Coruripe penetrando na superfície tabular, chegando próximo à cidade de Coruripe;

Área 2 - Unidades territoriais concentradas a partir do povoado de Barreiras, seguindo em duas estreitas faixas alinhadas, atingindo o povoado de Bebedouro, onde novamente, em Feliz Deserto, penetra para o interior.

Corresponde a uma área de terrenos areno-siltosos e/ou areno-argilosos dos tabuleiros e encostas laterais associadas. Nas feições falésias fósseis e reversos tabuliformes dissecados, de litologias terciárias do Grupo Barreiras em altitude predominante de 20-40m, é que foi registrada a situação de confronto entre os potenciais. O turismo de veraneio avança sobre essas áreas de domínio da cana-de-açúcar, caracterizando em disputa territorial pela ocupação. 


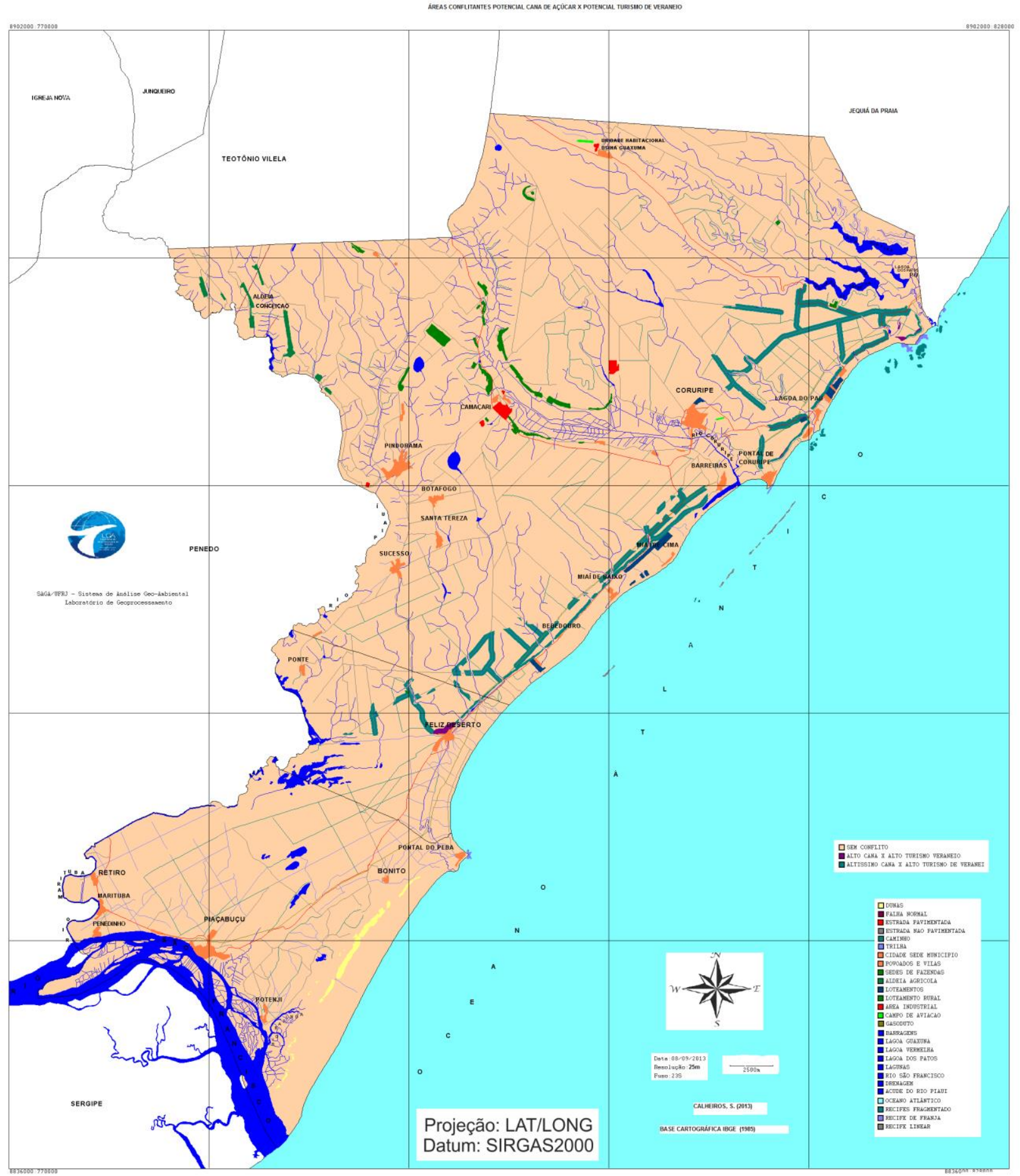

Figura 7: Áreas conflitantes potenciais cana de açúcar x potencial turismo de veraneio

Nesta área condições antrópicas estão associadas para penetração do turismo. Estrutura de serviços (água, energia, comunicação) pela proximidade de povoados, vilas e cidades (Coruripe e Feliz Deserto) e fácil acesso pela existência de estradas pavimentadas e 
não pavimentadas e caminhos, além da proximidade da praia e lagoas (Lagoa do Jequiá), são elementos de atração turística.

\section{CONFLITO ENTRE OS POTENCIAIS DE CANA-DE-AÇÚCAR E DE TURISMO DE FIM DE SEMANA}

As próprias características do turismo de fim de semana, conceituadas anteriormente, justifica a pouca expressividade territorial de ocorrência da situação analisada, como pode ser verificado na tabela 2 conforme planimetria e respectivas percentagens calculadas.

TABELA 2 - Resultado do Conflito dos Potenciais de Cana e Turismo de Fim de semana

\begin{tabular}{l|r|r}
\hline \multicolumn{1}{c|}{ CLASSES } & \multicolumn{1}{c}{ Há } & \multicolumn{2}{c}{ \% } \\
\hline SEM CONFLITO & 126398,00 & 99,9 \\
\hline ALTO CANA X ALTO TURISMO DE FIM-DE-SEMANA & 85,75 & 0,1 \\
\hline
\end{tabular}

A distribuição espacial ocorreu em 3 unidades territoriais descontínuas:

Área 1 - Estreita faixa paralela à praia, próximo aos Recifes de Franja;

Área 2 - Entre o povoado de Lagoa do Pau e Pontal de Coruripe;

Área 3 - Sul do povoado de Barreiras.

Área de domínio da cana-de-açúcar, devido às condições ambientais de solo e litologias terciárias do Grupo Barreiras, do reverso tabuliforme dissecado, em altitudes de 2040m. Nessas feições situação de conflito entre os potenciais foi registrada como se observa na figura 8. Representa área com condições antrópicas desfavoráveis ao turismo de fim de semana, com predomínio de estrada pavimentada, com proximidade de áreas urbanas, apresentando suporte de alimentação, pela presença de bares e restaurantes nas proximidades da praia. 


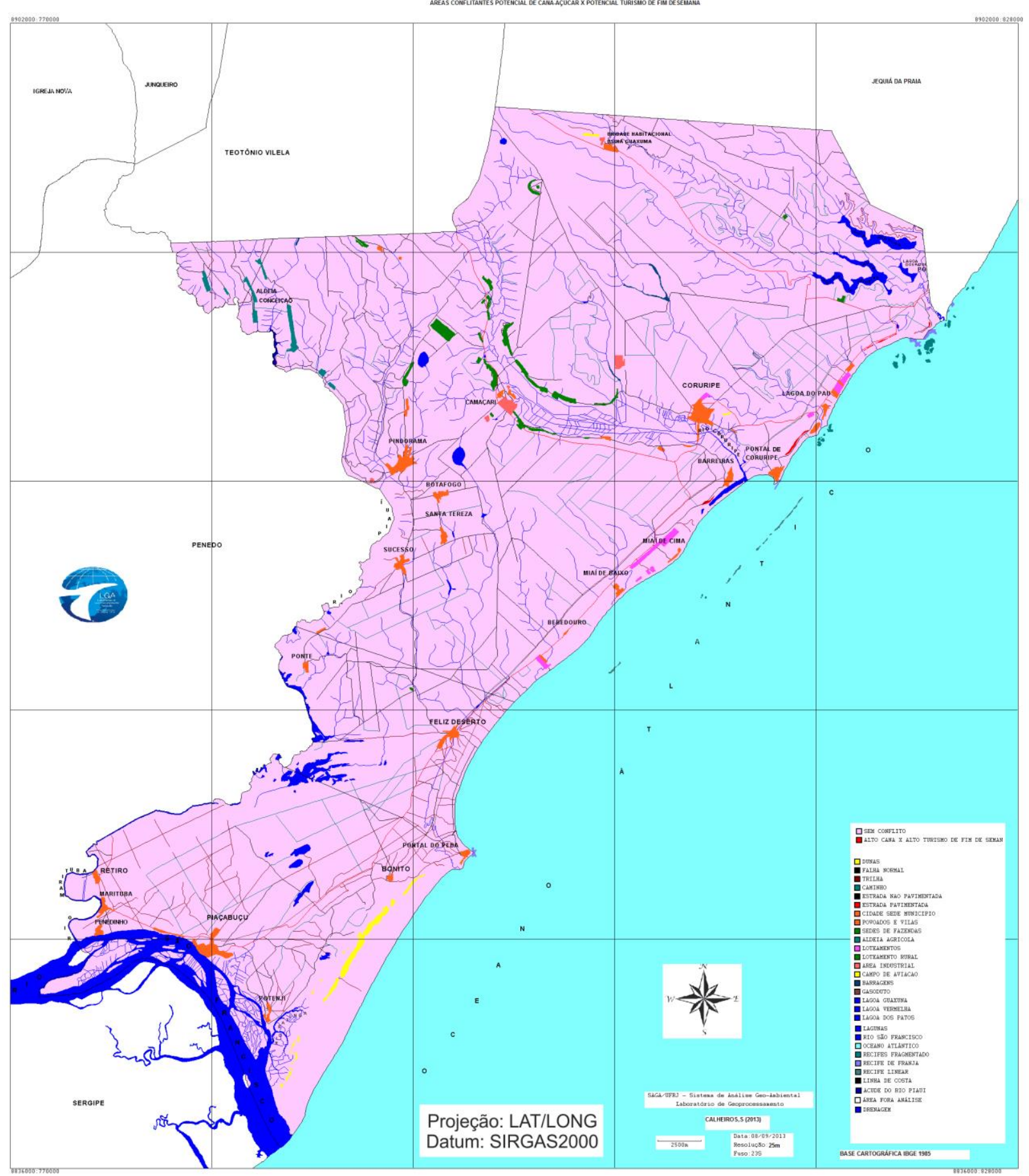

Figura 8: Áreas conflitantes potenciais cana-de-açúcar x potencial turismo de fim de semana 


\section{CONFLITO ENTRE OS POTENCIAIS DE CANA-DE-AÇÚCAR E TURISMO DE EMPREENDIMENTOS}

Apresenta área conflitante de maior expressão territorial, quando comparada aos subtipos anteriores, conforme tabela 3 muito embora se apresente na mesma faixa de ocorrência dos demais conflitos anteriormente identificados, como pode ser observado na figura 9. Sua localização demonstra a importante competição territorial entre a atividade agrícola tradicional e o turismo de empreendimentos. Disputam condições naturais e antrópicas comuns ao desenvolvimento de ambas as situações analisadas.

$\mathrm{Na}$ situação ambiental analisada, mesmo com extensão territorial de pouca expressividade em relação à área estudada, foram verificados registros de unidades territoriais com altíssimo e alto potencial conflitante, definidos em duas classes.

TABELA 3 - Resultado do Conflito dos Potenciais de Cana e Turismo de Empreendimento

\begin{tabular}{|c|c|c|}
\hline CLASSES & Há & $\%$ \\
\hline SEM CONFLITO & 124557,4 & 98,5 \\
\hline ALTO CANA X ALTO TURISMO DE EMPREENDIMENTO & 79,3 & 0,1 \\
\hline ALTÍSSIMO CANA X ALTÍSSIMO TURIMO DE EMPREENDIMENTO & 1847,1 & 1,4 \\
\hline
\end{tabular}

Apresenta distribuição em 3 áreas:

Área 1 - Unidades territoriais contínuas distribuídas sobre a rede viária, entre os povoados de Pontal de Coruripe;

Área 2 - Unidades territoriais distribuídas a partir do povoado de Barreiras, seguindo em duas estreitas faixas alinhadas, atingindo o povoado de Bebedouro, onde novamente, em Feliz Deserto, penetra para o interior;

Área 3 - Unidades territoriais descontínuas a leste do povoado de Duas Barras e norte da cidade de Feliz Deserto.

O cultivo de cana-de-açúcar desenvolve-se em terrenos areno-siltosos e/ou arenoargilosos dos tabuleiros e terraços fluviais associados. Nas feições de tabuleiros costeiros, em altitudes de 20-40m e litologias terciárias é que foram registradas situações de confronto entre os potenciais. O turismo de empreendimento avança sobre essas áreas de domínio da canade-açúcar, caracterizando em disputa territorial pela ocupação. Nesta área condições

Calheiros, Silva $2017 \quad$ ISSN 0104-5490 40


antrópicas estão associadas para penetração do turismo: a estrutura de serviços (água, energia, comunicação) pela proximidade de povoados e vilas e cidades (Coruripe e Feliz Deserto) e fácil acesso pela existência de estradas pavimentadas e não pavimentadas e caminhos.

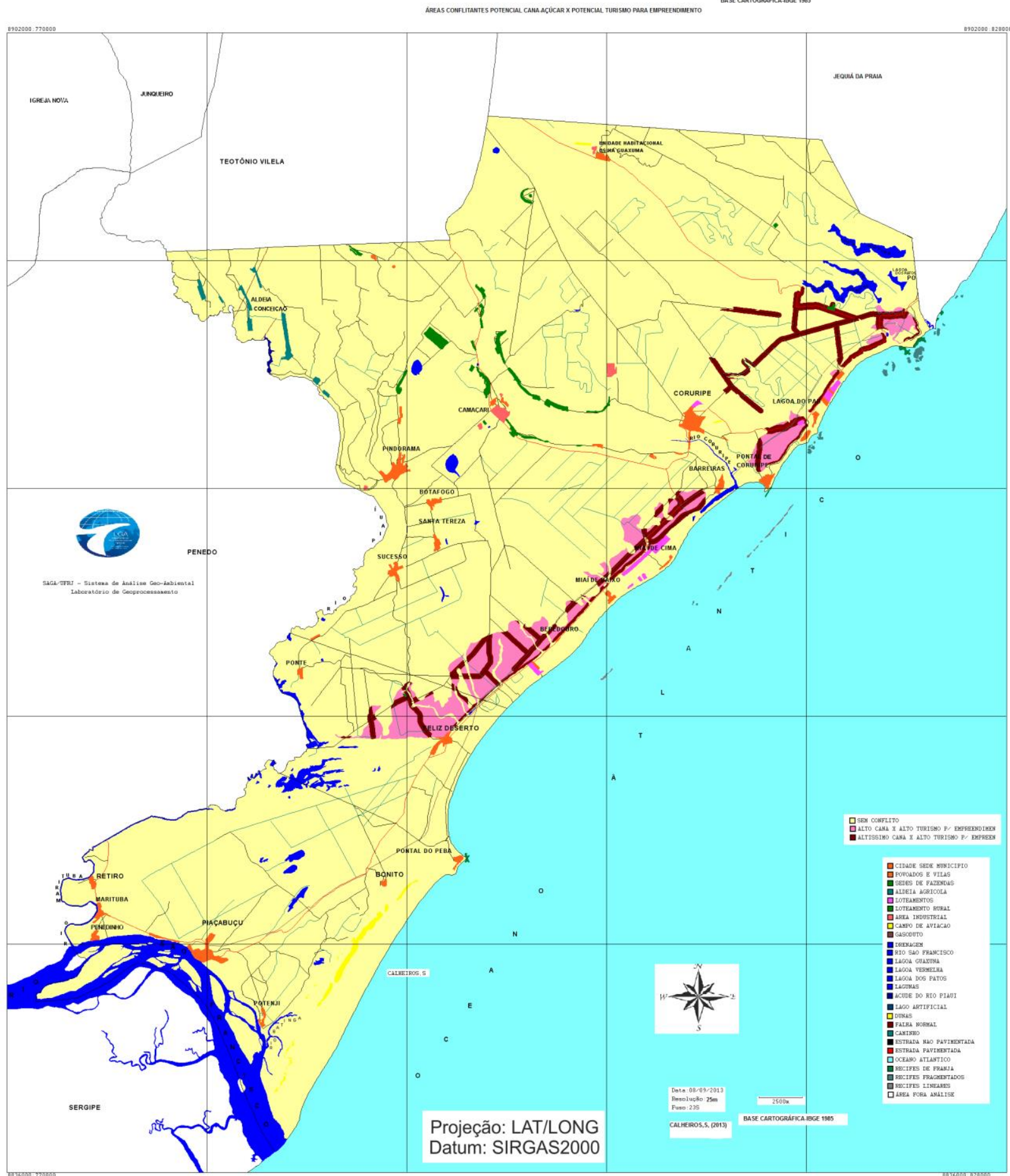

Figura 9: Áreas conflitantes potenciais cana-de-açúcar x potencial turismo de empreendimento 
O conflito de maior expressão territorial é entre os potenciais alto de cana e alto de turismo de empreendimento. Esse conflito ocorre na superfície tabular dominante, associada às áreas de encostas laterais e terraços colúvio-lagunares de vales afogados, sobre litologias terciárias em altitudes de 20-40m. Condições antrópicas estão associadas (estradas e núcleos urbanos), favoráveis à ocorrência das situações analisadas, principalmente para o turismo, pela proximidade de praias e lagoas.

A classe conflitante altíssimo cana e alto turismo de empreendimento também apresentam expressiva extensão territorial. Apresenta-se em falésias fósseis e reverso tabuliformes, sobre litologias terciárias do Grupo Barreiras, em faixas de altitudes de 20-40m, 40-60m e 60-80m. Essa penetração se estabelece em condições antrópicas favoráveis, de proximidades de estradas pavimentadas e não pavimentadas, tanto isoladamente como associadas a caminhos e trilhas, com estrutura de serviços devido à proximidade de povoados e vilas.

\section{CONSIDERAÇÕES FINAIS}

Ao longo dos séculos, a ocupação e uso do solo no estado de Alagoas sempre estiveram centralizados na cana-de-açúcar, traduzindo-se em constantes, porém lentas transformações ambientais.

Inicialmente, vista pela derrubada da Mata Atlântica, para uso da madeira em construções e fornalhas dos engenhos e usinas, como também para a expansão da área cultivada. Porém, a mais recente transformação proveniente da expansão agrícola canavieira, reveste-se de maior ordem de grandeza. Trata-se da expansão dos canaviais sobre os tabuleiros costeiros, que não só levou a alterações no uso e ocupação do solo, mas trouxe consigo um novo modelo visto pela incorporação de novas tecnologias e métodos de produção no campo agrícola e agroindustrial. Houve deslocamento do modelo agrícola autárquico para um modelo agrícola dependente de tecnologia, ou seja, atrelado aos setores que lhe fornecem insumos e/ou adquirem seus produtos, consolidados nos complexos agroindustriais. Em relação à agricultura do coco, também esse fato se verificou, mesmo em menor escala, na incorporação das novas tecnologias (irrigação) no campo.

Todavia, o estado de Alagoas como um todo, ainda permaneceu, no final do século $\mathrm{XX}$, com a atividade produtiva centrada na agricultura. É dentro deste contexto que o turismo se estabeleceu como alternativa econômica no estado, provocando alterações na organização 
do espaço alagoano, principalmente em sua fachada litorânea, resultando em importantes novas relações territoriais. Especificamente no segmento litorâneo sul, estas foram determinadas pelos fatores físico e socioeconômico, abaixo relacionados.

- Estratégico posicionamento deste setor litorâneo com relação aos fluxos rodoviários (norte-sul) e interioranos (via rio São Francisco);

- Quadro natural ainda pouco explorado pelo turismo, se comparado ao litoral centro-norte e norte;

- As novas interações espaciais associadas à expansão do turismo em uma área tradicionalmente agrícola, dominada principalmente pela agricultura da cana-deaçúcar e coco.

Por outro lado, o poder público se apresenta como ordenador de políticas de desenvolvimento e desarticulador da estrutura de poder político estadual. Isto se verifica:

- Em parte, perda dos incentivos federais; houve uma reestruturação da agroindústria sucroalcooleira em busca de produtividade e diversidade em suas atividades, o que contribuiu com o fechamento de algumas unidades (destilarias) e/ou uma reengenharia das mesmas (plantio de verão da cana).

- Pelas políticas de desenvolvimento turístico, com o Programa de Desenvolvimento Turístico - PRODETUR, favorecendo diretamente à atividade turística e, consequentemente, à expansão do turismo no estado. Isto favoreceu a busca de espaços para estabelecer os empreendimentos ligados a esta atividade.

Inevitavelmente, as relações de trabalho com a população local e a organização no espaço começam a manifestar mudanças, pois agora a mão de obra, nitidamente rural, incursiona em atividades terciárias e urbanas propiciadas pela expansão do turismo. Tendo em vista que a agricultura praticada na área possui um caráter sazonal, a nova atividade poderá absorver a mão de obra local, apresentando-se como uma possibilidade de ganho extra pela abertura de novas frentes de trabalho que compensem a época ociosa decorrente da sazonalidade das culturas ali desenvolvidas. Por isto, se para a atividade turística existirá uma condição de conflito pela disputa do espaço da agricultura (a terra), uma vez que os produtores de cana, álcool e coco continuavam proprietários das terras; o mesmo não é válido para a população, pois surge uma interação bastante positiva. 
Agrava-se a relação conflituosa devido ao suporte econômico e político atrelado a cada atividade. A cana-de-açúcar, por ser historicamente detentora do poder econômico e político local dos fornecedores de cana e indústrias do açúcar e álcool, detém a propriedade das terras (latifundiários). O turismo de empreendimento, de suporte econômico atrelado a empresas hoteleiras de capital nacional e internacional, precisa para se estabelecer do capital "terra", de propriedade do capital local canavieiro.

O conflito se aprofunda, inclusive veiculado pelo poder público, quando este se apresenta como ordenador de políticas de desenvolvimento turístico, (PRODETUR). Esta situação remete à desarticulação do poder político local que, para manter a hegemonia econômica e política, se reorganiza.

Os conflitos entre potenciais ambientais não foram analisados em exaustão, pelo fato de que as análises apresentadas atingiram os objetivos ficando para serem motivos de outra investigação. Todavia, os resultados apresentados permitem compreender claramente a influência da expansão do turismo na área de estudo, tradicionalmente dominada pela agricultura.

A expressiva potencialidade da área para o cultivo da cana de açúcar (alto e altíssimo), seguida do cultivo do coco, comprovam a importância destas culturas para a economia local. Também, constata-se a expressiva potencialidade da área para a expansão turística para os diferentes tipos de turismo. Porém, o turismo de empreendimento apresentou maior área de alto potencial, seguido do turismo de veraneio e de fim-de-semana.

Entretanto, as áreas identificadas de alto potencial turístico estão rebatidas sobre as áreas de uso tradicionalmente agrícola, cana-de-açúcar e coco, demonstrando alta ocorrência de situações territoriais conflitantes para a expansão turística, com implicações de ordem política e econômica nas relações territoriais de uso e ocupação do solo. Isto se deve ao fato de que os tipos de turismo de empreendimento e veraneio, além do uso dos recursos ambientais, necessitam de extensão territorial para estabelecer sua base de sustentação (ocupação).

O turismo de fim-de-semana é semelhante, porém com menor uso do solo para se estabelecer, podendo até mesmo utilizar os espaços existentes do turismo de veraneio e de empreendimentos.

Neste contexto, a proposta metodológica utilizada é potente e ao mesmo tempo simples de compreender e aplicar, dando respostas imediatas em concordância com um mundo dinâmico, onde a velocidade de ocorrência das transformações exige estruturas de 
avaliação ambiental aplicáveis a qualquer SGI. Isto em parte, também é favorecido pelo SAGA/UFRJ que possui algoritmos de grandes possibilidades de análise. Por outro lado, verifica-se a necessidade de uma discussão teórica, conceitual e terminológica, pois em algumas referências bibliográficas são utilizados termos e conceitos que se confundem.

Verifica-se que a utilização de SGIs é viável em qualquer área que permita georreferenciar a informação, tratando-a como uma informação territorial. A avaliação ambiental como procedimento metodológico apoiado no uso da tecnologia de SGIs, portanto baseado no geoprocessamento dos dados ambientais, permite a análise de forma detalhada espacial e taxonômica, de situações ambientais. O domínio da utilização de Sistemas Geográficos de Informação em Análise Ambiental, atualmente, inclui uma diversidade de aplicações, ampliando-se cada vez mais o uso de novas tecnologias.

\section{REFERÊNCIAS}

ALVES, D.S. Sistemas de informação geográfica. In: Simpósio Brasileiro de Geoprocessamento, São Paulo. Anais Simpósio Brasileiro de Geoprocessamento. São Paulo. USP - Escola Politécnica. 1990. p.66-87

BARRETO, M. Manual de iniciação ao estudo do turismo. Campinas (SP): PAPIRUS, 1995. 163p. (Coleção Turismo)

BECKER, B. Políticas e planejamento do turismo no Brasil. In: E. Yázigi; A. F. A. Carlos \& Rua de C. A. da Cruz.(org). Turismo: espaço, paisagem e cultura. São Paulo: HUCITEC, 1996. p.181-192.

CALHEIROS, Silvana Q. C. Base de dados geográfica: potencial para cana-de-açúcar, potencial de turismo fim de semana, turismo de Veraneio e turismo empreendimento. Rio de Janeiro: UFRJ. (Programa de Pós-Graduação em Geografia- Tese de Doutorado) Rio de Janeiro; 2000. Tomo um

CALHEIROS, Silvana Q. C. Impactos na Cobertura Vegetal no Complexo Estuarino. Lagunar Mundaú-Manguaba de 1995 a 1989/90. Rio Claro, UNESP. 136 p. (Tese Mestrado: UNESP - Campus Rio Claro, 1993).

CALHEIROS, Silvana Q. C. O Litoral Alagoano um espaço geográfico em transformação acelerada. Rio Claro: UNESP. 1991. 30 p. (Exame Qualificação - Mestrado). 
DE LA TORRE, O. El turismo, fenômeno social. México: Fondo de Cultura Econômica. 1992.

PADILHA, OT. El turismo fenômeno social. México: Fondo de Cultura Econômico. Sección de Obrais de Sociologia, 1990

RODRIGUES, A.B. Turismo e espaço: rumo a um conhecimento transdisciplinar. São Paulo: HUCITEC. 1997. 58p.

. Desafios para os estudiosos do turismo. In: , org. Turismo

e Geografia; reflexões teóricas e enfoques regionais. São Paulo: HUCITEC. 1996. p. 17-32.

XAVIER-DA-SILVA. SGIs: uma proposta metodológica. IN: LAGEOP-CEGEOP. Rio Janeiro: 1999. (Multimídia)

XAVIER-DA-SILVA, J; CARVALHO-FILHO, L. M. Sistemas de informação geográfica: uma proposta metodológica. In: Conferência sobre sistemas de informação geográfica, 6, simpósio brasileiro de geoprocessamento, 2. São Paulo, (SP). Anais... São Paulo: EPUSP, 1993. P.609-628.

XAVIER DA SILVA, J. Geoprocessamento e análise ambiental. Revista Brasileira de Geografia, (RJ), v.54, n.3, p.47-61, 1992.

XAVIER-DA-SILVA, J. Paralelos e reflexões. Rio de Janeiro: UFRJ - IGEO Depto Geografia, 1988. 172 p. (Concurso para Professor Titular). 